\title{
Entre o nomológico e o acidental: objeções à teoria regularista das leis da natureza
}

\section{Between nomological and accidental: objections to the regularity theory of laws of nature}

\begin{abstract}
Renato Cesar Cani
Doutorando em Filosofia pela Universidade Federal de Santa Catarina
\end{abstract}

(UFSC/CAPES)

Resumo: Neste artigo, analiso a concepção das leis da natureza denominada regularismo. O regularismo é definido aqui como uma versão de antirrealismo nomológico, isto é, a posição segundo a qual a fundamentação das leis da natureza deve ser feita mediante considerações de ordem epistêmica (e não metafísica). Segundo a proposta de Mill, Ramsey e Lewis, as leis da natureza são generalizações pertencentes a sistemas dedutivos capazes de equilibrar otimamente os requisitos de simplicidade teórica e força dedutiva. Com essa formulação, os defensores do regularismo esperam solucionar o problema da identificação, dificuldade que se apresenta a qualquer teórico que pretenda apresentar uma concepção razoável das leis. Trata-se da tarefa de fornecer um critério adequado para distinguir entre generalizações de caráter nomológico e generalizações acidentais. Meu objetivo é argumentar que a solução regularista do problema da identificação é inconsistente com os seus próprios pressupostos. Por fim, 
apresento e critico a tentativa de solução proposta por Lewis (1983), que tem como base a postulação de propriedades naturais.

Palavras-chave: Leis da natureza; Regularismo; Melhor sistema; Problema da identificação; David Lewis.

Abstract: In this paper, I analyze the regularity approach to the laws of nature. The regularity theory is here defined as a version of nomological antirealism, i.e. the view according to which laws of nature must be grounded by epistemic considerations (and not metaphysical ones). According to the proposal advanced by Mill, Ramsey and Lewis, the laws of nature are generalizations belonging to deductive systems that optimally balance the requirements of theoretical simplicity and deductive force. Through this formulation, the upholders of the regularity view hope to solve the identification problem, which is a difficulty that every philosopher who aims to provide a reasonable conception of laws encounters. It consists in providing an adequate criterion in order to distinguish between nomological and accidental generalizations. In this paper, I will defend that the regularity solution to the identification problem is inconsistent with its very own assumptions. I will also present and criticize Lewis' solution (1983), which is based on the postulation of natural properties.

Keywords: Laws of nature; Regularity; Best system; Identification problem; David Lewis.

$* * *$

\section{Introdução ${ }^{1}$}

É comumente admitido que tanto a experiência cotidiana como a experimentação científica nos permitem observar padrões e, a partir deles, formular determinadas generalizações.

$1 \quad$ O presente trabalho foi realizado com apoio da Coordenação de Aperfeiçoamento de Pessoal de Nível Superior - Brasil(CAPES) - Código de Financiamento 001. Agradeço a Eduardo S. O. Barra, por discussões frutuosas que resultaram no presente trabalho. Agradeço, também, ao parecerista anônimo da Revista Princípios, por valiosas indicações e correções. 
Tais uniformidades são utilizadas para fundamentar nossas expectativas de que, nas condições apropriadas, tais padrões irão se repetir. Se estivermos em condições normais de temperatura e pressão, é provável que esperemos que a generalização "Toda amostra de água ferve a $100^{\circ} \mathrm{C}$ " se mantenha verdadeira. De modo análogo, acreditamos que princípios fundamentais como a lei da gravitação de Newton, a lei dos gases ideais, a lei de Ohm e o princípio da exclusão de Pauli sejam bem fundamentados por observações e experimentos realizados sucessivamente. Tais princípios são usualmente classificados como leis devido à sua abrangência, à sua função explicativa (no domínio científico ao qual se referem) e, certamente, à nossa expectativa de que eles expressem regularidades necessárias.

Tradicionalmente, as leis têm sido pensadas pelos filósofos da ciência em termos de universalidade (ou grau de generalidade) e necessidade. Por exemplo, a lei dos gases ideais se aplica a qualquer sistema que atenda às condições que permitam representá-lo aproximadamente como um gás ideal (grosso modo, gases de baixa densidade submetidos a altas temperaturas). De acordo com tal lei, há uma correlação fixa de proporcionalidade entre as variáveis de estado (pressão, volume, temperatura) de um gás. À medida que essa lei se aplica a uma grande variedade de sistemas, podemos afirmar que se trata de um princípio geral. Ao mesmo tempo, parece que essa lei descreve certas relações necessárias entre grandezas mensuráveis: dado um gás à temperatura $T$ e submetido à pressão $p$, então seu volume será necessariamente igual a $k T / p$, sendo $k$ a constante de Boltzmann. A análise da lei dos gases ideais aponta, portanto, na direção do caráter geral e necessário das leis. Consideremos outro exemplo. A teoria da relatividade einsteiniana postula a impossibilidade de que qualquer sinal viaje mais rápido do que a velocidade da luz. Logo, para todo sinal, é necessário que sua velocidade seja menor ou igual de determinado valor fixo. Igualmente, a generalidade e a modalidade estão presentes nessa análise. Todos esses exemplos são consensualmente referidos como leis científicas, na medida em que podem ser interpretados como enunciados gerais que ex- 
pressam regularidades e que desempenham uma função explicativa no domínio científico ao qual pertencem. ${ }^{2}$

No entanto, se levarmos a sério as contribuições de David Hume acerca da ideia de conexão necessária (bem como das ideias de causa e efeito), notaremos que o caráter necessário das leis científicas é altamente problemático. A experiência repetida nos autoriza a inferir somente generalizações contingentes, uma vez que o caráter necessário de determinada lei não pode ser acessado empiricamente. Ora, isso cria dificuldades importantes para uma caracterização adequada das leis. Intuitivamente, diríamos que há diferenças claras entre as generalizações usualmente classificadas como leis científicas e as generalizações verdadeiras de modo acidental. A famosa oposição de Reichenbach entre os enunciados "Todas as esferas de urânio possuem diâmetro menor do que $1 \mathrm{~km}$ " e "Todas as esferas de ouro possuem diâmetro menor do que $1 \mathrm{~km}$ " capta essa intuição, ao mesmo tempo em que expõe um problema que deve ser resolvido pelos que desejam fornecer uma concepção filosófica das leis da natureza. ${ }^{3}$

O problema de distinguir entre generalizações nomológicas (verdadeiras em virtude de uma lei) e generalizações acidentais (verdadeiras de modo contingente) tem sido denominado pela literatura filosófica como problema da identificação (cf. van Fraassen, 1989). Por um lado, defensores do realismo nomológico procuram uma fundamentação ontológica para solucionar tal problema, sustentando que as leis expressam re$2 \quad$ Certamente, nem todas as leis são claramente derivadas de observações empíricas e generalizações. Muitas delas só são formuláveis por meio de cálculos matemáticos complexos. Ainda assim, podemos dizer que boa parte das leis - mesmo as que tem origem em modelos matemáticos - permitem que sejam deduzidas certas correlações entre grandezas, as quais tomamos como regularidades.

3 A intuição captada por Reichenbach é a de que os enunciados mencionados possuem a mesma forma lógica e (muito provavelmente) o mesmo valor de verdade, mas diferem quanto ao estatuto nomológico. Afinal, a instabilidade do urânio impede que haja esferas tão grandes desse elemento. Por outro lado, não há nada na constituição do ouro que impeça que exista uma esfera de ouro com diâmetro superior a $1 \mathrm{~km}$. Parece, então, que o primeiro enunciado é verdadeiro em virtude de uma lei, ao passo que o segundo é verdadeiro acidentalmente. 
lações necessárias entre universais (cf. Armstrong, 1983) ou essências disposicionais de objetos ou propriedades (cf. Bird, 2007; cf. Ghins, 2013). Por outro, defensores do antirrealismo nomológico sustentam - com base em considerações de matriz empirista - a impossibilidade de fundamentar a ideia de lei numa base metafísica. Segundo essa visão, o conceito de lei da natureza deve ser abandonado (cf. Giere, 1999) ou, em alternativa, fundamentado numa base sistemática e epistêmica. A versão de antirrealismo nomológico que abordarei no presente trabalho - o regularismo neohumeano - defende precisamente essa última alternativa. Segundo a proposta de Mill, Ramsey e Lewis, as leis da natureza são generalizações pertencentes a sistemas dedutivos capazes de equilibrar otimamente os requisitos de simplicidade teórica e força dedutiva. O conteúdo das leis, portanto, não ultrapassa as uniformidades e, como veremos, a solução do problema da identificação é epistêmica.

Nas primeiras duas seções, reconstruo algumas ideias principais do regularismo, quais sejam, a ideia de superveniência humeana e a teoria do melhor sistema. Na terceira seção, procuro mostrar que a solução regularista ao problema da identificação é inconsistente com os seus próprios pressupostos. Na quarta seção, abordo a tentativa de Lewis (1983) de reformular a concepção regularista com base na postulação de propriedade natural. Por fim, concluo o artigo criticando tal postulação.

\section{Superveniência humeana ${ }^{4}$}

A concepção regularista das leis da natureza parte das reflexões de Hume acerca das relações de causa e efeito. Tanto no Tratado da Natureza Humana (2009[1739]) quanto nas Investigações acerca do entendimento humano (1998[1748]), o autor argumenta que a observação repetida das regularidades nos revela, apenas, a conjunção constante de determinados tipos de evento, mas não o fato de que haja conexões necessárias

$4 \quad$ As seções $1,2,3,4$ e 5 do presente artigo correspondem a uma versão revisada e ampliada do segundo capítulo de minha Dissertação de Mestrado, que discorre sobre algumas das principais concepções de lei da natureza na filosofia da ciência contemporânea (cf. Cani, 2017). 
entre eles. Por exemplo, a experiência é capaz de nos mostrar que o fogo é usualmente seguido de fumaça, mas não que o fogo causa ou produz a fumaça. Afinal, o conteúdo das informações que nos são dadas pelos sentidos é, por si só, incapaz de fundamentar a inferência da relação de causalidade a partir da regularidade. Segundo Hume, portanto, mesmo na eventualidade de que os objetos possuam poderes ou disposições - como a suposta disposição do fogo para produzir fumaça - ou que haja conexões necessárias entre as coisas, tais realidades (caso existam) não são acessíveis ao entendimento, isto é, não estão disponíveis ao nosso conhecimento. Por esta razão, Hume classifica as ideias de poder, força ou conexão necessária como incertas e obscuras (cf. Hume, 1998[1748], p. 97).

Os comentadores de Hume divergem acerca do estatuto das conexões necessárias no pensamento do autor, ponto que não explorarei neste artigo. ${ }^{5}$ No entanto, autores regularistas tem buscado fundamentar suas concepções deflacionistas acerca das leis e da causalidade a partir das conclusões humeanas. É o caso de David Lewis, autor que lança mão da ideia de superveniência humeana a fim de articular sua interpretação das leis. Com efeito, Lewis chega a afirmar que grande parte do seu trabalho pode ser resumida como uma tentativa de defesa e aplicação da superveniência humeana. O filósofo enuncia essa tese nos seguintes termos:

[A] Superveniência humeana é nomeada em homenagem ao maior dos críticos das conexões necessárias. Trata-se da doutrina de que tudo o que há no mundo é um vasto mosaico de questões de fato particulares, apenas uma pequena coisa seguida de outra. (Lewis, 1986, p. ix).

Em que consiste o "mosaico de questões de fato particulares" mencionado por Lewis? No âmbito da filosofia humeana, os raciocínios sobre questões de fato se opõem às relações de ideias. Enquanto as relações de ideias estão sujeitas somente ao princípio de não-contradição, as questões de fato requerem

$5 \quad$ Para uma discussão e crítica acerca da interpretação regularista de Hume, no que tange as ideias de conexão necessária e causalidade, ver Kemp Smith (1941), Strawson (1989) e Barra (2012). 
verificação pela experiência. ${ }^{6}$ Nesse sentido, seja um conjunto de objetos $\{a, b, c, \ldots, n\}$ tais que os eventos $\{F a \& G a\},\{F b \&$ $G b\}, \ldots,\{F n \& G n\}$ sejam o caso. Ora, sempre será possível que exista um objeto $y$ tal que $\{F y \& \sim G y\}$ seja o caso. Desse modo, a observação jamais será suficiente para postular a existência de uma conexão necessária entre as propriedades $F$ e $G$. Logo, a afirmação de Lewis implica que a estrutura básica do nosso mundo é composta pelas questões de fato, isto é, por eventos particulares que podem ser expressos pela fórmula $P x$ (em que $P$ é uma propriedade e $x$ é um objeto). A sucessão de tais eventos dá origem ao que Lewis denomina mosaico humeano.

Na sequência da passagem citada acima, Lewis fornece mais detalhes a respeito da superveniência:

Consideremos a geometria: um sistema de relações externas de distância espaço-temporal entre pontos. Sejam eles pontos do próprio espaço-tempo, porções pontuais de matéria, éter ou campos, ou ambos. E, nesses pontos, temos qualidades locais: propriedades intrínsecas perfeitamente naturais que precisam de apenas um ponto para serem instanciadas. Em resumo: o que temos é uma configuração de qualidades. E é apenas isso. Não existe qualquer diferença se não houver diferença na configuração das qualidades. Todo o restante é superveniente desta base (Lewis, 1986, p. x).

Nas seções finais, aprofundaremos o que Lewis compreende por "propriedades intrínsecas perfeitamente naturais". Por ora, basta-nos compreender que a tese do mosaico humeano equivale à afirmação de que a estrutura básica do nosso mundo consiste na distribuição das qualidades locais no espaço e no tempo. Mais precisamente, trata-se da estrutura fundamental de mundos como o nosso, isto é, a definição inclui todos aqueles mundos nos quais a superveniência humeana seja válida. Uma vez estabelecida a estrutura do mundo por meio da ideia de mosaico, a superveniência pode ser enunciada como a tese segundo a qual todo enunciado verdadeiro acerca do nosso mundo é tornado verdadeiro pela configuração das qualidades locais dos particulares. Dito de outro modo, o modo como

$6 \quad$ Exemplificando: enquanto o enunciado "O triângulo $\mathrm{ABC}$ tem três lados" expressa uma relação de ideias, a sentença "Este quadro é verde" expressa uma questão de fato. 
as propriedades e relações espaço-temporais são instanciadas pelos objetos define tudo o que ocorre no mundo (cf. Lewis, 1994, p. 473). Todo o restante - i.e. as relações de causalidade, de probabilidade objetiva, e as leis da natureza - existe apenas de modo derivado. As leis da natureza, portanto, são supervenientes da história do mundo, isto é, do conjunto de acontecimentos dados no espaço e no tempo. À medida que a história do mundo inclui as regularidades - compreendidas como padrões recorrentes no modo de instanciação das propriedades - podemos dizer que, nessa visão, as leis da natureza são supervenientes às regularidades. Disso decorre o emprego do termo regularismo pela literatura filosófica.

Penso que dois pontos sobre a ideia de superveniência merecem destaque. Em primeiro lugar, Lewis afirma que a superveniência humeana é uma tese contingente. Trata-se de uma conjectura a respeito da estrutura do nosso mundo, isto é, a respeito da base a partir da qual as modalidades sobrevêm. Porém, a superveniência não é válida a priori, de modo que é admissível que existam outros mundos possíveis em que relações de necessidade sejam primitivas. ${ }^{7}$ A seguinte analogia ilustra esse ponto. Sejam dois mundos possíveis $w$ e $w^{\prime}$, tais que as configurações das qualidades locais (as propriedades e seu padrão de instanciação) sejam as mesmas nos dois mundos. Suponhamos que, em $w^{\prime}$ (mas não em $w$ ) haja relações modais, de forma que algumas das regularidades nesse mundo ocorram de modo necessário. Consequentemente, $w$ ' seria um mundo em que, por exemplo, a água ferve a $100^{\circ} \mathrm{C}$ necessariamente, ao passo que, em $w$, a água ferve a $100^{\circ} \mathrm{C}$ regularmente. Portanto, assumir a tese de Lewis significa negar que haja qualquer diferença entre $w$ e $w^{\prime}$, uma vez que, entre mundos possíveis como o nosso - i.e. mundos nos quais a superveniência é o caso - só há diferenças se houver diferenças na configuração das qualidades locais (cf. Lewis, 1994, p. 475). Como $w$ e $w^{\prime}$ possuem o mesmo arranjo de propriedades qualitativas, ambos descrevem, na realidade, o mesmo mundo possível. Só haveria

\footnotetext{
$7 \quad$ Mundos possíveis em que existam relações entre universais à la Armstrong (cf. 1983) ou disposições à la Bird (cf. 2007) são exemplos de mundos possíveis em que a superveniência humeana não é o caso.
} 
diferença entre $w$ e $w$ ' se negássemos a superveniência humeana. Na seção seguinte, exploraremos as consequências dessa afirmação para a teoria lewisiana das leis.

Em segundo lugar, Lewis admite que a superveniência humeana é inspirada na visão de mundo da física clássica, com suas partículas-ponto, propriedades e distâncias espaciais. No entanto, o autor afirma que defender a superveniência não acarreta comprometimento ontológico com as propriedades postuladas pela física clássica. Afinal, a física moderna sustenta diferentes versões acerca de quais são as propriedades fundamentais da natureza. Lewis afirma que, independentemente de qual seja a verdadeira descrição das propriedades do universo, o defensor da superveniência alega, somente, que as propriedades modais são supervenientes desta base qualitativa. Definir o conteúdo desta base, por outro lado, é tarefa da física, não da filosofia: "[d]efender a superveniência humeana não é defender uma física reacionária, mas resistir aos argumentos filosóficos que sustentam a existência de outros objetos além daqueles com os quais lida a física" (Lewis, 1994, p. 474). Em última análise, trata-se de um programa empirista e antirrealista nomológico, isto é, uma postura cética com relação às teorias metafísicas que postulam a existência de categorias como necessidades internas, relações entre universais ou disposições no intuito de solucionar problemas filosóficos.

Até aqui, vimos que a tese da superveniência indica a posição teórica das leis da natureza no quadro regularista: as leis são supervenientes da história no mundo. No entanto, falta esclarecer o que é uma lei da natureza, tarefa que cumprirei na próxima seção.

\section{A teoria do melhor sistema}

De acordo com o regularismo, a estrutura fundamental do nosso mundo é determinada pelo mosaico humeano de questões de fato particulares. Naturalmente, é possível encontrar padrões nesse mosaico, isto é, padrões no modo como as 
propriedades espaço-temporais são instanciadas. Tais padrões são aquilo que denominamos regularidades. Naturalmente, há filósofos que acreditam que a ocorrência das regularidades deva ser explicada. Muitos deles sustentam que a existência de leis é o que explica as regularidades. No entanto, vimos que o defensor da superveniência humeana nega que haja algo para além das regularidades. Em vez de identificar as leis com alguma categoria metafísica externa às regularidades, os autores regularistas definem as leis como proposições que meramente descrevem as regularidades factuais. Trata-se da identificação das leis aos axiomas de um sistema dedutivo ideal (Mill), ou de modo mais geral, aos axiomas ou teoremas do melhor sistema dedutivo ideal (Lewis). Ao longo desta seção, discutirei os fundamentos desta teoria para, nas seções seguintes, criticá-la.

A teoria regularista do melhor sistema costuma ser denominada concepção MRL, em homenagem aos filósofos que a propuseram, a saber: John Stuart Mill, Frank Ramsey e David Lewis. Como vimos, essa abordagem se situa no campo do antirrealismo nomológico, uma vez que lei da natureza não corresponde a uma categoria real/metafísica que se acrescenta às regularidades; ao contrário, o estatuto de lei corresponde a uma propriedade que algumas regularidades exibem e outras não.

De modo geral, os filósofos regularistas partem do pressuposto de que a natureza exibe certo padrão regular. Para Mill, a aparente uniformidade com que as coisas ocorrem na natureza é resultado da soma de várias regularidades pontuais, isto é, de padrões envolvendo objetos e circunstâncias de um mesmo tipo. Desse modo, Mill afirma:

A essas diversas uniformidades, quando obtidas por raciocínios indutivos considerados suficientes, denominamos, em linguagem corrente, Leis da Natureza. Cientificamente falando, este título é empregado de modo mais restrito, a fim de designar as uniformidades quando reduzidas à sua expressão mais simples. (Mill, 1974[1843], p. 315).

Em seguida, Mill menciona exemplos da mecânica clássica em que determinadas generalizações são obtidas dedutivamente a partir de generalizações ainda mais abrangentes. 
Segundo o autor, somente estas últimas merecem o título de lei da natureza. Nessa abordagem, a tarefa dos cientistas seria estabelecer, indutivamente, o menor conjunto de leis capazes de acarretar todas as uniformidades. A ideia de que haveria um sistema dedutivo com essas características é expressa por Mill nos seguintes termos:

\begin{abstract}
Ainda de acordo com outro modo de expressão, a questão: 'quais são as leis da natureza?' pode ser posta do seguinte modo: 'quais são as suposições menos numerosas e mais simples que, sendo aceitas, acarretariam toda a ordem existente na natureza?' Dito de outro modo: qual seria o menor conjunto de proposições gerais a partir das quais todas as uniformidades existentes no universo poderiam ser inferidas dedutivamente? (Mill, 1974[1843], p. 317).
\end{abstract}

Uma primeira consequência dessa análise é que, ao contrário do que ocorre com as concepções realistas das leis, a teoria regularista não se encontra ameaçada pelo problema da inferência. Esse problema corresponde à tarefa de explicar de que modo a proposição " $P$ é uma lei" acarreta $P$, sendo $P$ uma proposição que expressa uma regularidade e " $P$ é uma lei" a atribuição do estatuto de lei a esta regularidade. De acordo com a passagem citada acima, se $P$ descreve uma lei, então $P$ é um teorema ou axioma pertencente a um sistema dedutivo que acarreta todas as regularidades conhecidas. Podemos dizer que o problema da inferência não emerge para o regularismo, uma vez que ele só aparece quando se supõe haver uma distinção entre lei e regularidade.

Por outro lado, o problema da identificação traz dificuldades muito mais sérias à abordagem regularista. Afinal, as considerações de Mill não são suficientes para distinguir as generalizações acidentais das generalizações nomológicas, isto é, daquelas válidas em virtude de uma lei. Dito de outro modo, é perfeitamente possível imaginar um conjunto de axiomas, nos moldes descritos por Mill, tal que suas proposições acarretem os dois tipos de regularidades. Nesse sentido, o critério dedutivo parece incapaz de demonstrar a distinção entre regularidades com o estatuto de lei e regularidades fortuitas. Consideremos as seguintes proposições: 
(A) Todas as esferas de urânio possuem diâmetro menor que $1 \mathrm{~km}$, e

(B) Todas as esferas de ouro possuem diâmetro menor que $1 \mathrm{~km}$.

Intuitivamente, parece que a primeira regularidade merece o estatuto de lei, ao contrário da segunda. Afinal, são as propriedades radioativas do urânio que tornam impossível a constituição de uma esfera tal como descrita em (A); propriedades essas que não são compartilhadas pelo ouro. Todavia, Mill afirma apenas que o conjunto de axiomas deve ser capaz de acarretar "todas as uniformidades existentes no universo". Logo, é razoável supor que um sistema com tais características acarretaria (A) e (B), resultando na admissão de (B) como uma lei (ou de uma proposição similar a (B), de caráter mais geral).

Tentando solucionar este problema, Ramsey imagina uma situação hipotética em que conheceríamos tudo o que ocorre no universo. Em outras palavras, conheceríamos todo o mosaico humeano e os padrões regulares que ele exibe. Nesse cenário, Ramsey argumenta que organizaríamos todo esse conhecimento da maneira mais simples possível:

[...] mesmo que conhecêssemos todas as coisas, continuaríamos desejando sistematizar o nosso conhecimento por meio de um sistema dedutivo, e os axiomas gerais desse sistema seriam as leis fundamentais da natureza. A escolha dos axiomas será, em alguma medida, arbitrária, porém, se alguma simplicidade for preservada, a ocorrência de um corpo fundamental de generalizações tem menos probabilidade de ser arbitrária, algumas delas serão tomadas como axiomas e outras serão deduzidas (Ramsey, 1978[1928], p. 131).

Em relação à proposta de Mill, a inclusão do critério de simplicidade por Ramsey é um avanço explicativo, uma vez que esse critério pode apontar uma alternativa de tratamento ao problema da identificação. Nessas condições, podemos concluir que um sistema dedutivo como o de Ramsey incluiria informações acerca das propriedades radioativas do urânio, acarretando a proposição (A). Desse modo, (A) possuiria o estatuto de 
lei (ao menos, de uma lei derivada). Em contrapartida, para deduzir a proposição (B), é necessário que se considerem fatos particulares acerca do mundo, uma vez que nenhuma característica geral do ouro (ou dos metais em geral) exclui a possibilidade de que haja esferas de ouro com diâmetro elevado. Contudo, se respeitarmos a condição de simplicidade postulada por Ramsey, fatos particulares não seriam incluídos no conjunto de axiomas, pois isto tornaria o sistema mais complexo. Portanto, o conjunto de leis não acarretaria (B), fazendo com que essa proposição não possua o estatuto de lei.

Embora o critério de simplicidade torne a escolha dos axiomas menos arbitrária, o próprio Ramsey reconhece a permanência de certa arbitrariedade. Nesse sentido, Lewis (1973) propõe uma reformulação da teoria de Ramsey, apresentando o conceito de melhor sistema. Em primeiro lugar, Lewis considera desnecessária a suposição - proposta por Ramsey - de que conheçamos tudo o que ocorre na natureza. De acordo com Lewis, independentemente daquilo que saibamos acerca do universo, existem (na condição de objetos abstratos) inumeráveis sistemas dedutivos verdadeiros que satisfazem as condições impostas por Mill e Ramsey. Naturalmente, cada um desses sistemas possui um conjunto diferente de axiomas. A pergunta que não é respondida pelos dois autores citados é a seguinte: qual destes conjuntos de axiomas deve ser escolhido como o conjunto das leis da natureza? A fim de responder a esta questão, Lewis recorre às ideias de simplicidade e força. Dentre os sistemas dedutivos verdadeiros, alguns deles são mais fortes do que outros, isto é, possuem mais informações acerca do mundo. Imaginemos, por exemplo, um sistema em que todas as proposições verdadeiras acerca do mundo sejam tomadas como axiomas. Certamente, tal sistema seria o mais forte de todos, mas também o menos simples. Por outro lado, consideremos um sistema composto por um único axioma, e.g. " $1+1=2$ ". Apesar de muito simples, tal sistema fornece pouquíssima (ou nenhuma) informação acerca do mundo, isto é, trata-se de um sistema fraco. Partindo do pressuposto de que as virtudes de simplicidade teórica e força dedutiva tendem a se opor, Lewis afirma que o 
sistema dedutivo a ser adotado como o sistema das leis da natureza é aquele que melhor equilibra essas duas virtudes. Logo,

[...] uma generalização contingente é uma lei da natureza se, e somente se, ela aparece como um teorema (ou axioma) em cada um dos sistemas dedutivos verdadeiros que realizam o melhor equilíbrio entre simplicidade e força. De modo análogo, uma generalização é uma lei num mundo $W$ se, e somente se, ela aparece como um teorema em cada um dos melhores sistemas dedutivos verdadeiros em $W$ (Lewis, 1973, p. 73).

As leis da natureza são, portanto, as proposições do sistema que atinge o melhor equilíbrio entre as virtudes de simplicidade e força. Desse modo, ambos os requisitos devem ser aplicados à totalidade dos sistemas dedutivos verdadeiros. A fim de atingir o equilíbrio requerido, Lewis afirma que há padrões na própria ciência - nem sempre claros o suficiente - que indicam como isso é feito. Contudo, o autor alega que a falta de um padrão rígido que defina os termos segundo os quais o melhor equilíbrio seja atingido não representa uma desvantagem para sua concepção. Ao contrário, Lewis afirma que sua teoria explica a dificuldade e o caráter vago que ronda as discussões sobre a ideia de lei, uma vez que não há certeza sobre a existência efetiva de um sistema dedutivo que cumpra os requisitos do melhor sistema. Em última análise, o melhor sistema é um objeto ideal.

Antes de passar às críticas a essa concepção, vejamos quais supostas vantagens Lewis (1973, p. 74-75) enumera a partir da análise apresentada. Em primeiro lugar, o autor alega que a teoria do melhor sistema é consistente com a abordagem humeana segundo a qual as leis da natureza são contingentes. Afinal, num dado mundo possível, uma proposição pode fazer parte do melhor sistema (seja como teorema ou como axioma), mas essa mesma proposição pode, em outro mundo possível, ser uma proposição acidentalmente verdadeira (i.e. que não figura nem como axioma nem como teorema do melhor sistema) ou até mesmo uma proposição universal falsa. Logo, o melhor sistema define as leis apenas para o mundo possível no qual o sistema é formulado. Certamente, essa vantagem é re- 
lativa, pois a mesma conclusão é vista por realistas como uma fraqueza do regularismo. Em segundo lugar, Lewis considera que a teoria do melhor sistema se coaduna bem com a prática científica efetiva, visto que sua análise explica porque os cientistas são autorizados a tomar teoremas de teorias bem-sucedidas como leis, ainda que provisoriamente. Isto é, a atividade teórica é caracterizada como a tentativa de refinar os sistemas dedutivos, gradativamente, na direção do melhor sistema. Em terceiro lugar, esta concepção das leis possui aplicações na análise das similaridades entre mundos possíveis, tema fundamental na obra de David Lewis. ${ }^{8}$ De modo geral, mundos possíveis que compartilham um número maior de leis são mais similares a mundos cujas leis são radicalmente diferentes.

A quarta vantagem que Lewis atribui à sua teoria é o fato de que ela oferece uma solução ao problema epistêmico da identificação. Dito de outro modo, o autor considera que a concepção das leis como melhor sistema é eficaz na distinção entre generalizações nomológicas e acidentais. Segundo o autor, somente as leis se ligam a outras proposições verdadeiras para formar sistemas dedutivos que satisfaçam os requisitos enunciados por ele. Retomemos os enunciados (A) e (B), sobre os quais tratamos anteriormente. Para que um sistema dedutivo acarrete (B), ele deve incluir informações muito específicas sobre as esferas de ouro no nosso mundo, o que faria com que o sistema em questão perdesse simplicidade, sendo preterido pelo critério de Lewis. Por outro lado, se um sistema dedutivo excluísse informações acerca das propriedades radioativas dos átomos de urânio, de modo a não acarretar (A), isso faria com que a força de tal sistema fosse comprometida. Isso porque acreditamos que as propriedades radioativas do urânio - que

\footnotetext{
8 Com efeito, David Lewis se notabilizou pela defesa do realismo de mundos possíveis: "[à] medida que não posso acreditar que eu e meu entorno somos um conjunto de sentenças [...], também não posso acreditar que outros mundos sejam conjuntos de sentenças." (Lewis, 1973, p. 86). Neste trabalho, não analisarei o realismo de mundos possíveis de Lewis, uma vez que há consenso entre os filósofos de que a teoria do melhor sistema é consistente com uma visão deflacionista dos mundos possíveis, isto é, podemos aceitar a teoria regularista das leis e interpretar os mundos possíveis como ficções teóricas. A esse respeito, cf. van Fraassen, 1989, p. 62.
} 
impedem a existência de grandes esferas de tal elemento - são propriedades gerais de todos os elementos radioativos. Portanto, é razoável supor que esse tipo de informação figure nas teorias químicas e físicas como axiomas do melhor sistema, dado seu poder informativo. Com relação ao ouro, a não existência de grandes esferas de ouro só poderia ser explicada pela menção de fatores contingentes, talvez relacionados às condições em que tal metal é encontrado na natureza ou ao seu valor financeiro e material. Nada disso seria relevante para obter informações acerca de outros metais, por exemplo. Portanto, a inclusão de enunciados como (B) no rol das leis da natureza traria como consequência a multiplicação de axiomas sobre as condições particulares em que ouro, prata, bronze e outros metais se encontram na natureza, o que claramente reduz a simplicidade do sistema.

Logo, o melhor sistema - e, portanto, aquele que contém as leis da natureza como seus axiomas - deve incluir axiomas que acarretem (A) e excluir axiomas que acarretem (B). Desse modo, o problema da identificação estaria resolvido.

\section{O problema da identificação (I)}

A teoria do melhor sistema apresenta uma concepção deflacionista das leis da natureza. Ao invés de assumir alguma forma de realismo nomológico para explicar as uniformidades, os regularistas enfatizam a função sistemática das leis, concebidas como axiomas e teoremas pertencentes a um sistema dedutivo ideal. Vimos que esta visão, aliada à ideia de superveniência humeana, faz com que o regularismo solucione o problema da inferência por definição. Uma vez que o conteúdo das leis coincide com as regularidades, não há vazio teórico entre a lei e a sua instanciação particular. Por outro lado, a solução regularista do problema da identificação tem sido alvo de polêmicas entre os filósofos da ciência que se debruçam sobre o tema das leis. Nesta seção, discutirei três dificuldades enfrentadas pela teoria do melhor sistema, a saber: (i) a objeção de que as leis -regularistas não são explicativas; (ii) dificuldades relativas à 
definição dos critérios de simplicidade, força e equilíbrio; (iii) a dependência linguística do melhor sistema. Pretendo sustentar que essas três dificuldades comprometem a solução regularista para o problema da identificação.

Uma primeira objeção à teoria do melhor sistema - levantada por van Fraassen (cf. 1989, p. 40-64) e Mumford (cf. 2004, p. 19-49) - diz respeito ao fato de as leis-regularistas não serem explicativas. É de se esperar que uma teoria acerca das leis da natureza explicite de que modo aquilo que ocorre no mundo é explicado pela existência de leis. No entanto, ao perguntarmos: "Por que esta amostra de metal sofreu dilatação após ser aquecida?", a resposta "Porque a proposição segundo a qual todos os metais dilatam quando aquecidos faz parte do sistema dedutivo que melhor combina simplicidade e força" dificilmente seria considerada satisfatória. Isso ocorre porque a explicação depende do conteúdo informativo, isto é, uma explicação será considerada satisfatória se a informação mencionada por ela for relevante para o fato a ser explicado. Em última análise, afirmar que as leis fazem parte de uma teoria que explica os fatos não é equivalente a afirmar que as leis, elas mesmas, explicam.

Além disso, não está claro que as melhores teorias, de acordo com os critérios de Lewis, são as que mais explicam. Vimos que, segundo Lewis, as melhores teorias são aquelas que melhor combinam simplicidade e força. A escolha desses critérios, para o autor, está fundamentada na prática científica, visto que a história da ciência apresenta casos em que esses critérios desempenharam função relevante na escolha teórica. A esse respeito, van Fraassen (cf. 1989, p. 49) aponta que, analogamente, há relatos de casos em que os cientistas escolhem teorias segundo seu poder explicativo, independentemente de como se defina o conceito de explicação. Esse fato gera dois problemas para a teoria de Lewis. Primeiramente, o regularista deve estabelecer o vínculo entre simplicidade/força e explicação, pois este vínculo não é trivial. Em segundo lugar, se o regularista admitir o poder explicativo como um critério adicional, ao lado da simplicidade e da força, isto certamente modificará o 
melhor equilíbrio entre tais critérios. Afinal, há casos em que os cientistas optam por teorias mais explicativas e menos simples ou fortes. Logo, o melhor sistema - de acordo com os critérios de Lewis - pode não ser o mais explicativo. Consequentemente, as leis do melhor sistema podem não explicar os fatos.

A objeção (ii) concerne a suposta objetividade dos critérios de simplicidade, força e equilíbrio, dos quais dependem a análise proposta por Lewis. Diversos autores já apontaram que as noções de simplicidade e força são histórica e psicologicamente condicionadas, o que compromete a objetividade destes critérios (cf. Armstrong, 1983, p. 1-73). Ainda assim, é possível considerar que a explicação de Lewis para estes critérios parta de uma base intuitiva que poderia, sem maiores problemas, ser aceita por todos. Usualmente, se possuímos uma teoria simples e adicionamos informações para torná-la mais forte, sua simplicidade diminuirá. No entanto, o problema mais grave aparece quando analisamos a noção de equilíbrio. Afinal, Lewis não esclarece de que modo o equilíbrio entre simplicidade e força deve ser avaliado. Se as duas virtudes são opostas, em que ocasiões é justificável renunciar à força em detrimento da simplicidade ou vice-versa?

Mesmo que concedêssemos, para fins argumentativos, que o melhor equilíbrio entre simplicidade e força pudesse ser atingido de modo objetivo, haveria um problema adicional, o que nos leva à objeção (iii). Trata-se do que van Fraassen denomina invariância quanto à tradução: "[m]esmo que uma teoria verdadeira em nossa linguagem exiba, dentre as teorias formuladas nesta linguagem, a combinação ótima entre simplicidade e força, sua tradução para outra linguagem não irá, em geral, preservar esta virtude" (van Fraassen, 1989, p. 42). Suponhamos que um sistema dedutivo, formulado em determinada linguagem $L$, atinja o melhor equilíbrio entre simplicidade e força. Naturalmente, tal avaliação é dependente dos parâmetros estabelecidos pela linguagem $L$, uma vez que um sistema mais simples na linguagem $L$ pode não continuar simples após ser traduzido para determinada linguagem L'. O mesmo ocorre para a força ou o conteúdo informativo. Desse modo, a tra- 
dução de um sistema dedutivo de $L$ para $L$ modifica (ou pode modificar) o equilíbrio e, consequentemente, o melhor sistema.

As três objeções que vimos até aqui, em especial as duas últimas, comprometem os critérios propostos pela teoria do melhor sistema. Se os parâmetros de simplicidade, força e equilíbrio não são objetivos, além de serem dependentes da linguagem, então eles não são adequados para solucionar o problema da identificação. Em outros termos, simplicidade, força e equilíbrio - conforme Lewis os concebe - não bastam para distinguir as generalizações nomológicas das acidentais. Na seção seguinte, veremos a tentativa de Lewis (1983) de reformular sua teoria por meio da introdução da noção de propriedades naturais. Apesar disso, tentarei sustentar que esse conceito não basta para solucionar os problemas discutidos aqui.

\section{Propriedades naturais}

De acordo com a teoria regularista, as leis da natureza são os axiomas e teoremas do sistema dedutivo ideal que melhor combina as virtudes de simplicidade e força. Vimos, porém, que os critérios identificadores do melhor sistema dependem da linguagem na qual ele é formulado, fato que compromete a objetividade da concepção regularista. No artigo "New Work for a Theory of Universals" (1983), David Lewis revisa sua teoria das leis a fim de responder a esse tipo de objeção. Em linhas gerais, o autor propõe o que chama de teoria regularista seletiva, na qual as leis da natureza são as regularidades pertencentes ao melhor sistema desde que este seja formulado numa linguagem cujos predicados descrevam propriedades perfeitamente naturais. Nesse sentido, Lewis espera eliminar a arbitrariedade da aplicação dos critérios de simplicidade e força por meio da normalização da linguagem. Mas o que são propriedades naturais?

Em grande medida, o artigo de Lewis é uma resposta ao livro Universals and Scientific Realism (1978), escrito por David Armstrong. No primeiro volume desta obra, Armstrong argumenta contra as ontologias nominalistas e sustenta sua teoria aristotélica dos universais, compreendidos como abstrações de 
estados de coisas. Em breve, o principal argumento utilizado por Armstrong em favor do realismo (acerca de universais) é o de que a postulação da existência de universais é a única maneira de explicar satisfatoriamente as semelhanças objetivas entre objetos diferentes. De acordo com ele, portanto, ao predicarmos " $a$ possui a propriedade $F$ " e " $b$ possui a propriedade $F$ ", sendo $a$ e $b$ objetos distintos, a melhor explicação deste fato é admissão da existência do universal $F$ (cf. Armstrong, 1978, p. 11-18). Em última análise, os dois objetos literalmente possuem algo em comum, a saber, instanciam o universal $F$.

Comentando a obra de Armstrong, Lewis estabelece uma distinção entre propriedades e universais. Uma vez que os universais são compreendidos como entidades reais, eles dizem respeito às semelhanças objetivas existentes na natureza. Por outro lado, Lewis afirma que possuir uma propriedade significa somente ser membro de uma classe (Lewis, 1983, p. 343). Mas as classes podem ser definidas de forma arbitrária, de modo que as propriedades não capturam, necessariamente, as semelhanças objetivas entre os objetos. Por exemplo, podemos definir a classe - e a propriedade correspondente - dos objetos não-esféricos, ou a classe dos filósofos cujos nomes iniciam com a letra 'D', entre outras. Assim, parafraseando Platão, Lewis alega que "[a]s propriedades cortam a realidade nas suas articulações naturais, bem como em todos os outros lugares" (Lewis, 1983, p. 346).

Nesse cenário, o próprio Lewis reconhece que, admitindo somente as propriedades - e não os universais - sua ontologia abre margem para as objeções que vimos na seção anterior, sobretudo no que tange a aplicação indiscriminada dos critérios de simplicidade e força. Para ilustrar essa limitação, o autor formula um exemplo: suponhamos um sistema dedutivo $S$, e definamos o predicado $F$ como aquele que se aplica a todos os objetos do mundo no qual $S$ é válido, e somente a eles. Desse modo, podemos axiomatizar $S$ por meio de um único axioma, a saber, "xFx. Visto que o sistema contém um único axioma, ele é o mais simples possível. Por outro lado, como o predicado $F$ se aplica a todos os objetos alcançados pelo sistema em questão, 
então $S$ é também o mais forte possível. Assim, Lewis afirma: "a teoria ideal incluiria (i.e. seu axioma acarretaria estritamente) todas as verdades, e por conseguinte todas as regularidades. Logo, toda regularidade seria uma lei. Isto deve estar errado" (Lewis, 1983, p. 367). Em última análise, Lewis admite que a escolha arbitrária de um vocabulário primitivo não permite a identificação adequada das leis da natureza, como demonstrado por esse exemplo limite. Logo, o autor precisa impor algum tipo de restrição à linguagem na qual os sistemas dedutivos são formulados, eliminando a arbitrariedade da aplicação dos critérios de simplicidade e força.

A fim de cumprir esse objetivo, a proposta de Lewis é definir uma base mínima para caracterizar completamente o mundo e suas semelhanças objetivas. Porém, o autor deseja fazer isso sem comprometer-se com uma forma de realismo de universais à la Armstrong, considerado inflacionista por ele. A solução encontrada pelo autor consiste na postulação de uma distinção gradual entre propriedades e classes: algumas delas são perfeitamente naturais; outras, imperfeitamente naturais, de acordo com graus; outras, ainda, não-naturais. As propriedades perfeitamente naturais são aquelas que correspondem às semelhanças objetivas entre os objetos. Descobrir quais são essas propriedades é tarefa da física. Uma vez fixado este ponto de referência, as outras propriedades serão consideradas mais ou menos naturais por meio da comparação com as propriedades perfeitamente naturais (cf. Lewis, 1983, p. 347). Enquanto Armstrong explica as semelhanças objetivas entre objetos pela existência de universais, Lewis considera que a instanciação de uma propriedade natural por determinada classe de objetos é um fato primitivo. Trata-se, portanto, de um fato bruto, isto é, não suscetível a análises ulteriores. Logo, esse fato pode ser reconhecido sem implicar comprometimento com a existência de uma entidade, isto é, de um universal (cf. Lewis, 1983, p. 352).

Por meio da postulação das propriedades perfeitamente naturais, Lewis espera reformular sua teoria das leis, eliminando os problemas citados anteriormente. Assim, o melhor sistema deve ser procurado entre os sistemas formulados numa 
linguagem cujos predicados descrevam somente propriedades perfeitamente naturais. Trata-se de um critério de elegibilidade para o melhor sistema, como afirma Lewis:

Um padrão apropriado de elegibilidade não é difícil de encontrar: definamos que o vocabulário primitivo que aparece nos axiomas se refira apenas a propriedades perfeitamente naturais. [...] Se adotarmos essa proposta, ela terá como consequência o fato de que as leis tenderão a ser as regularidades envolvendo propriedades naturais. As leis fundamentais, tomadas como axiomas do sistema ideal, devem concernir apenas propriedades perfeitamente naturais (Lewis, 1983, p. 367-368).

Em última instância, a distinção gradual entre propriedades perfeitamente naturais e imperfeitamente naturais espelha a gradação entre os sistemas dedutivos. Entre dois sistemas dedutivos, sempre haverá um que combina melhor as virtudes de simplicidade e força; logo, esse sistema estará mais próximo do melhor sistema e, portanto, os predicados que aparecem em seus axiomas e teoremas serão mais próximos das propriedades perfeitamente naturais. As propriedades perfeitamente naturais serão aquelas que se referem aos predicados que aparecem no sistema que se apresenta como o melhor - a partir da comparação com os demais sistemas possíveis - de modo que seus axiomas e teoremas devam ser tomados como leis da natureza. De acordo com Lewis, portanto, fixar a referência dos predicados da linguagem na qual são formulados os sistemas dedutivos elimina a subjetividade da aplicação dos critérios de simplicidade e força. No entanto, o próprio autor admite que formular uma definição de simplicidade permanece uma questão complicada. Ainda assim, Lewis alega que esta seria uma questão ainda mais difícil de solucionar (ou até impossível) na ausência de um critério de elegibilidade para o melhor sistema. Além disso, o autor argumenta que a postulação de propriedades naturais é consistente com a prática científica, uma vez que os cientistas buscam descobrir as propriedades fundamentais dos objetos e o modo como elas se relacionam.

O caráter seletivo da nova teoria regularista de Lewis consiste no fato de que seu critério permite identificar quais 
regularidades merecem o estatuto de lei da natureza, a saber, aquelas envolvendo as propriedades naturais. Segundo o autor, o modo como está definido o melhor sistema conduz, automaticamente, às regularidades envolvendo as propriedades naturais: "o caráter nomológico de uma regularidade consiste apenas no fato de que ela se encaixa num sistema ideal de pontuação máxima, logo é inevitável que as leis possuam aquilo que é requerido para atingirem essa pontuação máxima." (Lewis, 1983, p. 377). À medida que as propriedades perfeitamente naturais são definidas como aquelas que correspondem às semelhanças objetivas da natureza, torna-se inevitável que as leis da natureza descrevam essas propriedades, uma vez que não integrariam o melhor sistema se descrevessem propriedades não-naturais. Naturalmente, devido ao caráter ideal do melhor sistema, tanto o conteúdo das leis quanto o conteúdo das propriedades naturais (i.e. quais e quantas são elas) permanece uma questão aberta, a ser discutida pela física.

\section{O problema da identificação (II)}

Retomemos nossa discussão acerca do problema da identificação. Vimos que o problema da inferência é solucionado de modo trivial pela concepção regularista das leis, uma vez que leis são tipos especiais de regularidade. Todavia, a teoria do melhor sistema se mostrou incapaz de solucionar o problema epistêmico da identificação, que consiste na tarefa de apresentar um critério para distinguir regularidades acidentais e regularidades que merecem o estatuto de lei. Segundo Lewis, a postulação das propriedades naturais elimina este problema, uma vez que somente são admitidas como leis aqueles enunciados cujos predicados envolvem propriedades perfeitamente naturais. Nessa seção, pretendo sustentar - seguindo a contribuição de van Fraassen (cf. 1989, p. 51-55) - que a reformulação da teoria regularista mantém as dificuldades associadas ao problema da identificação.

Na seção anterior, vimos que Lewis considera a instanciação de uma propriedade perfeitamente natural por deter- 
minada classe de objetos como um fato primitivo. Além disso, o autor afirma que é tarefa da física determinar quais são as propriedades perfeitamente naturais em nosso mundo. Porém, Lewis não oferece qualquer razão para fundamentar a crença de que as teorias físicas futuras serão formuladas numa linguagem mais correta (i.e. cujos predicados se refiram a propriedades mais naturais) do que as teorias anteriores. Dito de outro modo, o único critério oferecido por Lewis para acreditarmos que um predicado descreva uma propriedade natural é o fato de que ele ocorra em uma teoria física bem-sucedida. Disto decorre que, sempre que uma teoria física é substituída por outra, os predicados da nova teoria são mais naturais (i.e. mais próximos das propriedades perfeitamente naturais) do que os da teoria anterior. Mas isso não precisa ser assim. Como adverte van Fraassen, a substituição de teorias pode ocorrer por vários critérios: simplicidade, aplicabilidade, poder explicativo, etc. Logo, se a única evidência para crermos que um predicado descreva uma propriedade natural for o fato de que este predicado ocorre numa teoria bem-sucedida, então não temos razão para crer que o predicado seja natural de fato. Afinal, não há critério independente para a seleção dos predicados naturais. Van Fraassen resume essa objeção nos seguintes termos:

[...] caso realmente haja uma distinção objetiva entre classes naturais e não-naturais, e caso as leis (como concebidas por Lewis) sejam aquilo que a ciência espera formular a longo prazo, então a única evidência possível para o fato de que um predicado seja natural é o fato de que ele aparece numa teoria bem-sucedida. Se for assim, então não pode ser o caso que a ciência seja guiada - mesmo que parcialmente - pela seleção de propriedades naturais sobre as nãonaturais (van Fraassen, 1989, p. 53).

Em última análise, a postulação de propriedades naturais para suprir as lacunas presentes na teoria do melhor sistema carece de fundamentação independente. O melhor sistema é concebido como uma teoria ideal, a ser atingida quando a física atingir o seu pleno desenvolvimento (se é que isso ocorrerá um dia). Analogamente, as propriedades perfeitamente naturais também são concebidas idealmente. Trata-se das propriedades descritas pelos predicados da teoria física mais completa, ou seja, do me- 
lhor sistema. Ora, os critérios que guiam as escolhas e substituições de teorias são variados, não necessariamente conduzem às propriedades naturais imaginadas por Lewis. Se recusamos a postulação de propriedades naturais, recusamos também a solução regularista para o problema da identificação. Desse modo, o desafio de formular um critério capaz de distinguir as regularidades nomológicas das acidentais permanece em aberto.

\section{Conclusão}

A partir da ideia de superveniência humeana, a concepção regularista propõe uma visão deflacionista das leis da natureza. De acordo com Mill, Ramsey e Lewis, tudo o que há no mundo são regularidades. Algumas destas merecem o estatuto de lei da natureza, devido à sua função sistemática. No entanto, não se trata de dizer que há algum tipo de entidade na natureza (como universais ou disposições) para fundamentar as leis.

Ao longo deste artigo, apresentamos o regularismo como uma concepção deflacionista das leis da natureza. Uma vez que a identificação do conteúdo das leis às regularidades tornou complicada a tarefa de distinguir entre generalizações nomológicas e acidentais, Lewis apresenta uma reformulação: as leis devem ser formuladas em uma linguagem que empregue apenas predicados que descrevam classes naturais. De fato, vimos que a postulação das classes naturais é fracamente motivada por Lewis, de modo que há um elemento de circularidade na análise proposta pelo autor. Por um lado, as leis são definidas como as proposições que se referem às classes naturais. Por outro, as classes naturais são definidas como aquelas que aparecem nas leis da natureza. Logo, não há razões independentes para que acreditemos que determinado predicado seja natural.

Procurei enfatizar que o problema da identificação é a principal desvantagem da concepção regularista, uma vez que tal teoria carece de um critério independente para destacar as leis em meio às regularidades. Os problemas enfrentados pela teoria regularista fazem com que, recentemente, tenham surgido diversas tentativas de fundamentar as leis da natureza de 
modo realista. Em linhas gerais, os realistas recusam a metafísica humeana pelo fato que essa não captura a distinção entre leis e regularidades. Tais autores alegam que a fonte dos problemas enfrentados pelos regularistas reside no compromisso com a ideia de superveniência humeana.

$$
* * *
$$

\section{Referências}

ARMSTRONG, D. M. Universals and Scientific Realism. Vol I: Nominalism and Realism. Cambridge: Cambridge University Press, 1978.

ARMSTRONG, D. M. What is a law of nature? Cambridge: Cambridge University Press, 1983.

BARRA, E. S. O. Filosófica \& Natural: a dupla identidade da causalidade no Tratado de Hume. Filosofia Unisinos, v. 13, n. 2, 2012.

BIRD, A. Nature's metaphysics: laws and properties. Oxford: Clarendon Press, 2007.

CANI, R. C. Realismo nomológico e os problemas da identificação e da inferência. Curitiba, PR. Dissertação de Mestrado. Universidade Federal do Paraná, 2017, 125p.

GIERE, R. Science without laws. Chicago: The University of Chicago Press, 1999.

GHINS, M. Uma introdução à metafísica da natureza: representação, realismo e leis científicas. Trad. Eduardo Salles O. Barra e Ronei Clécio Mocellin. Curitiba: Editora UFPR, 2013.

HUME, D. Investigações acerca do entendimento humano. Trad. José Oscar de Almeida. São Paulo: UNESP, 1998[1748].

HUME, D. Tratado da natureza humana: uma tentativa de introduzir o método experimental de raciocínio nos assuntos morais. Trad. Déborah Danowski. 2. ed. São Paulo: UNESP, 2009[1739].

KEMP SMITH, N. The Philosophy of David Hume. London: Macmillan, 1941.

LEWIS, D. Counterfactuals. Cambridge: Harvard University Press, 1973.

LEWIS, D. Humean Supervenience Debugged. Mind, New Series, v. 103, n. 412, p. 473-490, 1994. 
LEWIS, D. New work for a theory of universals. Australasian Journal of Philosophy, v. 61, n. 4, p. 343-377, 1983.

LEWIS, D. Philosophical papers Vol. II. Oxford: Oxford University Press, 1986.

MILL, J. S. A System of Logic Ratiocinative and Inductive: Being a Connected View of the Principles of Evidence and the Methods of Scientific Investigation. Toronto: University of Toronto Press, 1974[1843]. (Collected Works of John Stuart Mill, Vols. VII and VIII).

MUMFORD, S. Laws in Nature. New York: Routledge, 2004.

RAMSEY, F. P. Universals of Law and of Fact. In: MELLOR, D. H.

(Org.) F. P. Ramsey, Foundations: Essays in Philosophy, Logic, Mathematics and Economics. London: Routledge, p. 128-132, 1978[1928].

STRAWSON, G. The Secret Connection: Causation, Realism, and David Hume. Oxford: Clarendon Press, 1989.

VAN FRAASSEN, B. Laws and symmetry. Oxford: Oxford University Press, 1989. 